\title{
Tribological Properties of Cyano-Based Ionic Liquids under Different Environments
}

\author{
Shouhei Kawada* and Shinya Sasaki \\ Tokyo University of Science, 6-3-1 Niijuku, Katsushika-ku, Tokyo 125-8585, Japan \\ *Corresponding author: Shouhei Kawada (s-kawada@rs.tus.ac.jp)
}

Manuscript received 30 January 2018; accepted 27 March 2018; published 15 July 2018

Presented at the 6th World Tribology Congress 2017 Beijing, September 2017

\begin{abstract}
Ionic liquids have been used as novel high-performance lubricants. However, fluorine-based ionic liquids cause corrosion of materials by the formation of $\mathrm{FeF}_{2}$ and $\mathrm{FeF}_{3}$. This study focuses on cyano-based ionic liquids, as they have low corrosion tendencies owing to the absence of fluorine in their structures. However, cyano-based ionic liquids are hydrophilic, and hence, the effect of ambient conditions (e.g., atmospheric moisture) on the tribological properties needs to be investigated. This study reports the tribological properties of two types of cyano-based ionic liquids 1-ethyl-3-methylimidazolium dicyanamide and 1-ethyl-3-methylimidazolium tricyanomethane under air, vacuum, and dry air environments. Their friction coefficients were found to be dependent on the ambient condition. Both the ionic liquids exhibited low friction coefficients in vacuum. The time-of-flight secondary ion mass spectrometry results indicated that the anion was adsorbed on the worn surface under vacuum conditions, and the adsorbed anion exhibited a low friction. In dry air, the cation was adsorbed on the worn surface, and the adsorbed cation exhibited a higher friction coefficient than the adsorbed anion. In air, the cyano-based ionic liquids caused corrosion of the sliding material and exhibited a high friction coefficient, because of the absorption of moisture from air.
\end{abstract}

\section{Keywords}

ionic liquid, vacuum, SEM-EDS, ToF-SIMS

\section{Introduction}

Ionic liquids are salts that exist in the liquid phase at room temperature [1-3]. They have been used as novel highperformance lubricants, because of their attractive properties, such as low vapor pressure, low volatility, high thermal stability, and high oxidation stability [4-7]. Most of the studies on ionic liquids as lubricants focus on fluorine-based ionic liquids, such as tetrafluoroborate, hexafluorophosphate, trifluoromethanesulfonate, and tris(perfluoroalkyl) trifluorophosphate [8-17]. Zinc dialkyldithiophosphate (ZDDP) is a well-known lubricant additive and exhibites good tribological properties [18-22]. Fluorine-based ionic liquids exhibit superior tribological properties than ZDDP, because of the formation of tribo-films composed of $\mathrm{FeF}_{2}$ and $\mathrm{FeF}_{3}$ during sliding [8-17, 23]. However, use of fluorine-based ionic liquids as a lubricant results in corrosion of metallic materials due to the formation of hydrogen fluoride $[8,24]$. Especially, tetrafluoroborate and hexafluorophosphate undergo hydrolysis when exposed to moisture and generate hydrogen fluoride even without sliding [25-27]. To prevent corrosion, use of fluorinefree ionic liquids, such as bis(oxalato)borate, ethylsulfate, diethylphosphate, dicyandiamide, tricyanomethane, and tetracyanoborate has been explored [28-33]. These ionic liquids do not have fluorine in their chemical strucutres, and therefore, they have a low risk of corrosion damage. The present study focuses on the use of cyano-based ionic liquids as lubricants. These ionic liquids are composed of light elements (e.g., hydrogen, boron, carbon, and nitrogen) and therefore, have a lower environmental impact than other types of ionic liquids [34]. As novel lubricants, they are promising alternatives to fluorine-based ionic liquids. Howerer, cyano-based ionic liquids are hydrophilic, and the effect of ambient conditions (e.g., atmospheric moisture) on the tribological properties needs to be invesitgated.

This paper reports the tribological properties of two types of cyano-based ionic liquids under air, vacuum, and dry air environments. Scanning electron microscopy/ energy dispersive X-ray spectroscopy (SEM-EDS) and time-of-flight secondary ion mass spectrometry (ToF-SIMS) techniques were used to characterize the worn surfaces.

\section{Experimental details}

2.1 Materials

Two types of cyano-based ionic liquids were used as 
Table 1 The molecular structures and the physical properties of the cyano-based ionic liquids

\begin{tabular}{|c|c|}
\hline & 1-ethyl-3-methylimidazolium dicyanamide [EMIM][DCN] \\
\hline Viscosity $\left(40^{\circ} \mathrm{C}\right)$ & $9.66[\mathrm{mPas}]$ \\
\hline Melting Point & $<-50\left[{ }^{\circ} \mathrm{C}\right]$ \\
\hline \multicolumn{2}{|l|}{$\begin{array}{l}\text { Structural } \\
\text { Diagram }\end{array}$} \\
\hline & 1-ethyl-3-methylimidazolium tricyanomethane [EMIM][TCC] \\
\hline Viscosity $\left(40^{\circ} \mathrm{C}\right)$ & $10.01[\mathrm{mPas}]$ \\
\hline Melting Point & $<-50\left[{ }^{\circ} \mathrm{C}\right]$ \\
\hline $\begin{array}{l}\text { Structural } \\
\text { Diagram }\end{array}$ & $\mathrm{H}_{3} \mathrm{C}^{-}$ \\
\hline
\end{tabular}

lubricants: 1-ethyl-3-methylimidazolium dicyanamide ([EMIM] [DCN]) and 1-ethyl-3-methylimidazolium tricyanomethane ([EMIM][TCC]). The molecular structures and the physical properties of the ionic liquids are listed in Table 1. Both [EMIM][DCN] and [EMIM][TCC] comprise the same cation, but structurally different forms of anions. [EMIM][DCN] and [EMIM][TCC] with purity $>98 \%$ and water content $<1000 \mathrm{ppm}$ were purchased from Merck Chemicals, Germany and IoLiTec, Germany, respectively. The viscosities of the ionic liquids were measured using a tuning-fork vibration viscometer (SV-1A, A\&D Company, Japan).

For the ball-on-disk sliding wear tests, a $\phi 24 \mathrm{~mm} \times t 7.9 \mathrm{~mm}$ disk and a $\phi 4 \mathrm{~mm}$ ball of AISI 52100 were used. The surface roughness $R_{\mathrm{a}}$ of both the disk and the ball was $0.05 \mu \mathrm{m}$.

\subsection{Sliding tests}

The tribological properties of the cyano-based ionic liquids under air, vacuum, and dry air conditions were evaluated using an atmosphere-controlled ball-on-disk friction tester [28]. Prior to the sliding tests, the specimens were ultrasonically cleaned with a mixed solution of petroleum benzine and acetone in the ratio of 1:1 for $20 \mathrm{~min}$. Thirty microliters of the ionic liquid was applied onto the surface of the disk. The operating parameters for the sliding tests were: temperature $=25^{\circ} \mathrm{C}$, load $=3.5 \mathrm{~N}$, sliding velocity $=52.3 \mathrm{~mm} / \mathrm{s}$, and test duration $=120 \mathrm{~min}$. For the sliding tests under air, the relative humidity was maintained at $50 \%$. Under vacuum conditions, the degree of vacuum was $2.0 \times 10^{-5} \mathrm{~Pa}$. For the sliding test under dry air, the enclosure was filled with dry air after vacuuming. All the sliding tests were repeated ten times, and the test results showed good reproducibility. The worn surfaces after the sliding tests were analyzed by optical microscopy (OM, VHX-100, Keyence, Japan).

\subsection{Analysis}

To identify the elements present on the worn surfaces of the disk specimens after the sliding tests, SEM-EDS (TM3030Plus, HITACHI, Japan) was employed using an accelerating voltage of $5 \mathrm{keV}$ and a magnification of 250X. The specimens for SEMEDS analysis were ultrasonically cleaned with a mixed solution of petroleum benzine and acetone in the ratio of 1:1 for $10 \mathrm{~min}$.

The chemical composition of the worn surfaces of the disk specimens was analyzed using ToF-SIMS (ULVAC TRIFT III, URVAC PHI, Japan) to confirm the adsorption of the ionic liquids on the worn surface. A pulsed electron impact ion source $\left(30 \mathrm{keV}, \mathrm{Au}^{3+}\right)$ was used to generate primary ions for the analysis.
The analysis area on the sample surface was $300 \mu \mathrm{m} \times 300 \mu \mathrm{m}$, and the ion irradiation time was $4 \mathrm{~min}$. The measured mass range was $0.5-2000 \mathrm{~m} / \mathrm{e}$, and the mass resolution was $1955 \mathrm{~m} /$ $\Delta \mathrm{m}$. The lateral resolution was $3 \mu \mathrm{m}$. The specimens for ToFSIMS analysis were ultrasonically cleaned with a mixed solution of petroleum benzine and acetone in the ratio of 1:1 for $10 \mathrm{~min}$.

\section{Results}

3.1 Tribological properties

Figure 1 shows the mean friction coefficient obtained during the last 5 minutes of the sliding tests under different environments. Both the cyano-based ionic liquids exhibit a high friction coefficient, $>0.1$, in air. In vacuum, both the cyano-based ionic liquids exhibit a relatively low friction coefficient, $<0.075$. The friction coefficients obtained after sliding in dry air are higher than those in vacuum and lower than those in air. [EMIM] [TCC] exhibits a lower friction coefficient than [EMIM][DCN] in air and vacuum.

Figure 2 shows the images of the worn surfaces of the ball and the disk specimens. The worn surfaces of the disk specimens lubricated with the two cyano-based ionic liquids turned black after sliding in air and dry air. Especially, corrosion of the disk specimen was observed in the case of [EMIM][DCN] after sliding in air. On the other hand, sliding in vacuum did not blacken the worn surfaces of the disk specimens.

The above results indicate that the ambient condition and the type of anion affect the tribological properties of the cyanobased ionic liquids.

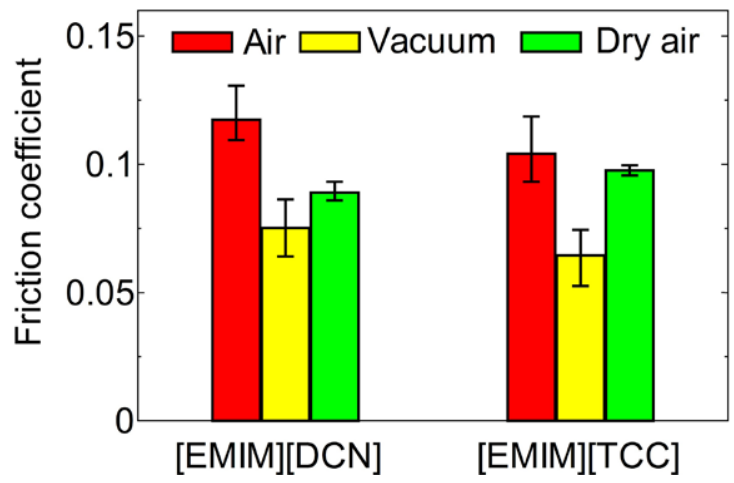

Fig. 1 The friction coefficient of cyano-based ionic liquids under different environment 


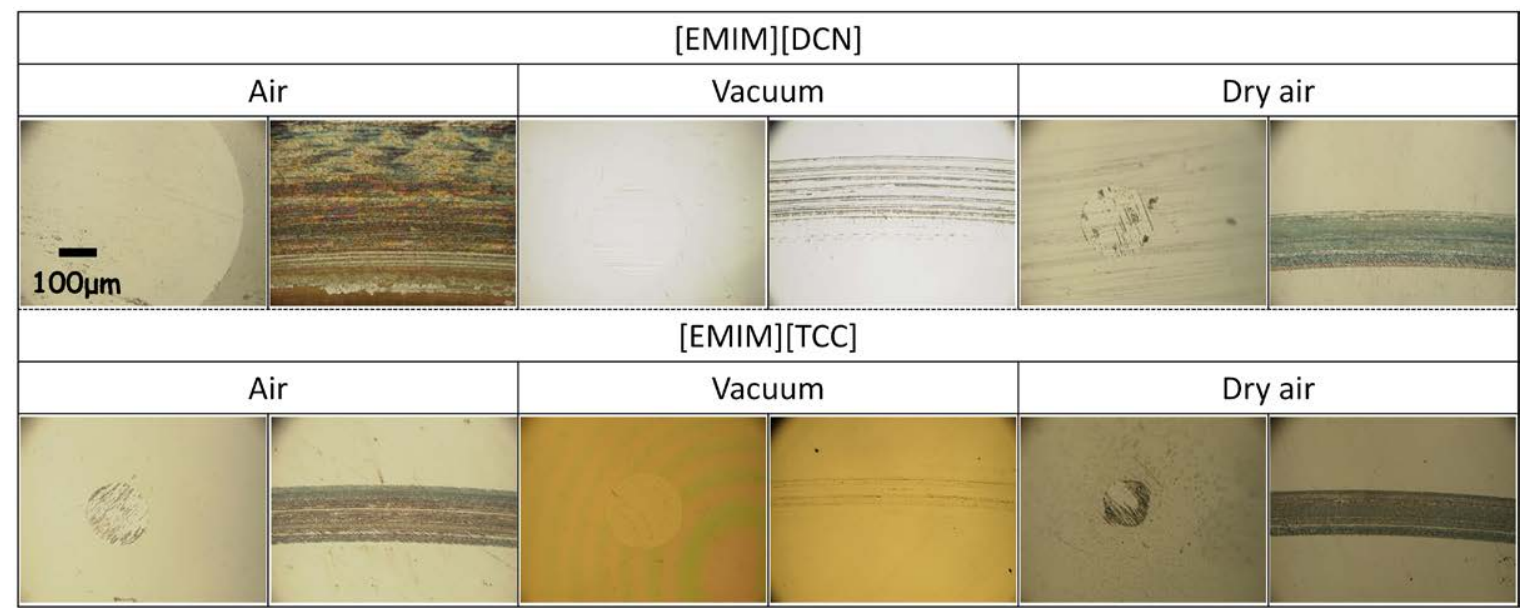

Fig. 2 The optical images of the worn surfaces of the ball and the disk specimens

\subsection{SEM-EDS analysis results}

Figure 3 shows the SEM-EDS mapping images of the disk specimens. SEM-EDS was used to analyze C K $\alpha 1$, N K $\alpha 1$, O $\mathrm{K} \alpha 1$, and $\mathrm{Fe} \mathrm{L} \alpha 1$ peaks. However, there were no significant differences in the C K $\alpha 1, \mathrm{~N} \mathrm{~K} \alpha 1$, and Fe L $\alpha 1$ peaks. Therefore,

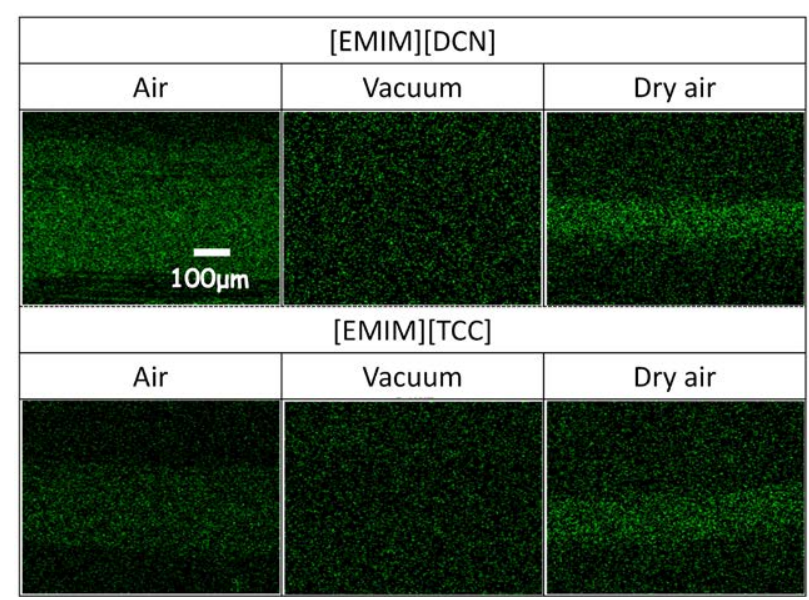

Fig. 3 The SEM-EDS mapping images of the disk specimens the mapping results of $\mathrm{O} K \alpha 1$ are shown in Fig. 3, which reveals the presence of oxygen on the worn surfaces lubricated with both the cyano-based ionic liquids for sliding in air and dry air. However, oxygen is not detected on the worn surface formed in vacuum. These results indicate that oxide film was removed or became thin by the sliding under vacuum conditions. On the other hand, oxide film was not removed by sliding or oxide film was formed again by the ambient environment under air and dry air conditions.

\subsection{ToF-SIMS analysis results}

To analyze the chemical composition of the worn surfaces of the disk specimens, mapping images of each ion ([EMIM] cation $=111 \mathrm{~m} / \mathrm{e},[\mathrm{DCN}]$ anion $=66 \mathrm{~m} / \mathrm{e}$, and $[\mathrm{TCC}]$ anion $=90 \mathrm{~m} / \mathrm{e})$ on the worn surface were obtained by ToF-SIMS, as shown in Fig. 4. The cation is adsorbed on the worn surface in the case of both the cyano-based ionic liquids under air and dry air conditions. On the other hand, the anions are not adsorbed on the worn surface. In vacuum, the anions of both the cyano-based ionic liquids are adsorbed on the worn surface. These results suggest that the adsorption behaviors of cyano-based ionic liquids depend on the ambient environment.

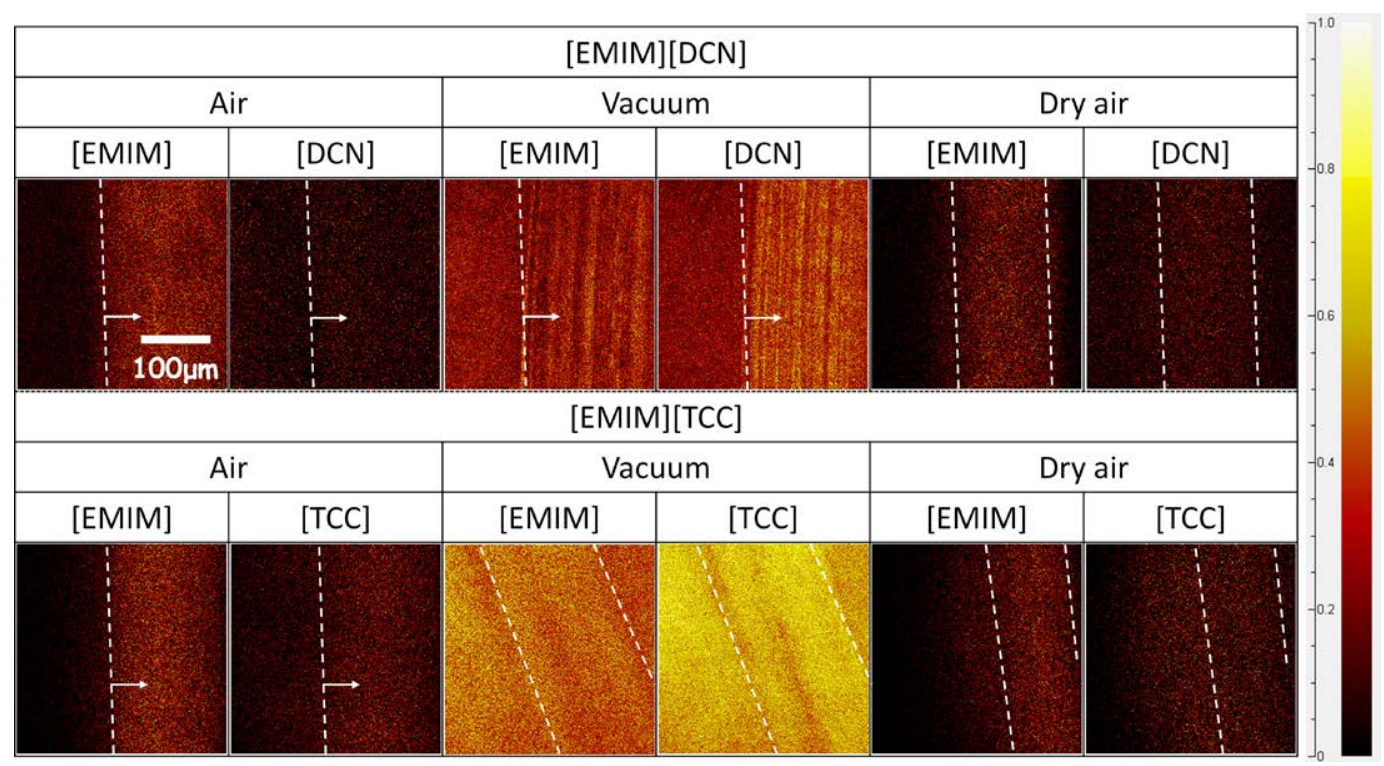

Fig. 4 The ToF-SIMS mapping images of the disk specimens 


\section{Discussion}

Both the cyano-based ionic liquids studied in the present work exhibited low friction coefficients during sliding in vacuum. The ToF-SIMS results showed that the anion is adsorbed on the worn surface. It is believed that the adsorption of anion results in good tribological properties. The reason for the adsorption of anion is explained as follows. According to the SEM-EDS analysis, the oxide film was removed by the sliding under vacuum conditions. This exposed the nascent surface, which functioned as a catalyst $[28,33,35,36]$. The cyano-based ionic liquids interacted with this nascent surface and underwent catalytic decomposition, during which only the anion was adsorbed on the worn surface because of electrical forces; nascent steel surfaces have positive charges [35, 37]. [EMIM][TCC] exhibited a lower friction coefficient than [EMIM][DCN], which is attributed to the good tribological properties of the [TCC] anion.

The friction coefficients of both the cyano-based ionic liquids in dry air were higher than those in vacuum. According to the SEM-EDS and ToF-SIMS results, the worn surface was covered by oxide film, and the cation was adsorbed on the oxide film. Hence, both the cyano-based ionic liquids underwent catalytic decomposition, because only cation was adsorbed on the worn surface. Subsequently, the nascent surface was covered with oxygen, and cation was adsorbed on the worn surface by interaction with oxygen. The [EMIM] cation exhibited poor tribological properties than the [DCN] and the [TCC] anions.

During sliding in air, both the cyano-based ionic liquids exhibited high friction coefficients. Especially, [EMIM][DCN] caused corrosion of the sliding material. The worn surface was covered with oxygen, and cation was adsorbed on the worn surface. These results are similar to those obtained for sliding in dry air; however, the friction coefficients are higher. Corrosive wear occurs when ionic liquids absorb moisture in air. Therefore, it is believed that the moisture in air adversely affected the tribological properties of the cyano-based ionic liquids.

\section{Conclusion}

The tribological properties of two different ionic liquids under air, vacuum, and dry air conditions were investigated using SEM-EDS and ToF-SIMS techniques.

The main conclusions are as follows:

(1) The friction coefficients of the ionic liquids were affected by the ambient condition.

(2) The lowest friction coefficient was obtained for sliding in vacuum. The anion was adsorbed on the worn surface by electrical interactions with the nascent surface. The adsorbed [TCC] anion exhibited a lower friction coefficient than the adsorbed [DCN] anion.

(3) Sliding in dry air resulted in the formation of oxide film on the worn surface. The cation was adsorbed on the oxide film by interactions with oxygen. The adsorbed [EMIM] cation exhibited a higher friction coefficient than the adsorbed $[\mathrm{DCN}]$ and $[\mathrm{TCC}]$ anions.

(4) Sliding in air resulted in corrosion and a high friction coefficient, because the ionic liquids absorbed the moisture in the air conditions.

\section{Acknowledgment}

This work was supported by a Grant-in-Aid from Japan Society for the Promotion of Science (JSPS; No. 15J05958,
JP16H02310, JP26630041).

\section{References}

[1] Walden, P., "Molecular Weights and Electrical Conductivity of Several Fused Salts," Bulletin of the Russian Academy of Sciences, 1914, 405-422.

[2] Wilkes, J. S. and Zaworokto, M. J., "Air and Water Stable 1-Ethyl-3methylimidazolium Based Ionic Liquids," Journal of the Chemical Society, 13, 1992, 965-967.

[3] Chauvin, Y., Mussmann, L. and Olivier, H., "A Novel Class of Versatile Solvents for Two-Phase Catalysis: Hydrogeneation, Isomerization, and Hydroformylation of Alkenes Catalyzed by Rhodium Complexes in Liquid 1, 3-Dialkylimidazolium Salts," Angewandte Chemie International Edition in English, 34, 23-24, 1996, 2698-2700.

[4] Matsumoto, H., Yanagida, M., Tanimoto, K., Nomura, M., Kitagawa, Y. and Miyazaki, Y., "Highly Conductive Room Temperature Molten Salts Based on Small Trimethylalkylammonium Cations and Bis(trifluoromethylsulfonyl)imide," Chemistry Letters, 8, 29, 2000, 922-923.

[5] Wilkes, J. S., "A Short History of Ionic Liquids - From Molten Salts to Neoteric Solvents," Green Chemistry, 4, 2002, 79-80.

[6] Rogers, R. D. and Seddon, K. R., "Ionic Liquids - Solvents of the Future?," Science, 302, 2003, 792-793.

[7] Seddon, K. R., "Ionic Liquids: A Taste of the Future," Nature Materials, 2, 2003, 363-365.

[8] Kondo, Y., Yagi, S., Koyama, T., Tsuboi, R. and Sasaki, S., “Lubricity and Corrosiveness of Ionic Liquids for Steel-on-Steel Sliding Contacts," Proceedings of the Institution of Mechanical Engineers, Part J: Journal of Engineering Tribology, 226, 2012, 991-1006.

[9] Ye, C., Liu, W., Chen, Y. and Yu, L., "Room-Temperature Ionic Liquids: A Novel Versatile Lubricant," Chemical Communications, 2001, 2244-2245.

[10] Kamimura, H., Kubo, T., Minami, I. and Mori, S., "Effect and Mechanism of Additives for Ionic Liquids as New Lubricants," Tribology International, 40, 4, 2007, 620-625.

[11] Bermudez, M. D., Jimenez, A. E., Sanes, J. and Carrion, F. J., “Ionic Liquids as Advanced Lubricant Fluids," Molecules, 14, 8, 2009, 28882908.

[12] Canter, N., "Using Dicationic Liquids as High Temperature Lubricants," Tribology \& Lubrication Technology, 63, 5, 2007, 12-13.

[13] Phillips, B. S., John, G. and Zabinski, J. S., "Surface Chemistry of Fluorine Containing Ionic Liquids on Steel Substrates at Elevated Temperature Using Mössbauer Spectroscopy" Tribology Letters, 26, 2, 2007, 85-91.

[14] Suzuki, A., Shinka, Y. and Masuko, M., "Tribological Characteristics of Imidazolium-Based Room Temperature Ionic Liquids under High Vacuum," Tribology Letters, 27, 3, 2007, 307-313.

[15] Minami, I., "Ionic Liquids in Tribology," Molecules, 14, 2009, 22862305.

[16] Kinoshita, H., Kondo, M., Nishina, Y. and Fujii, M., “Anti-Wear Effect of Graphene Oxide in Lubrication by Fluorine-Containing Ionic Liquid for Steel," Tribology Online, 10, 1, 2015, 91-95.

[17] Kamimura, H., Chiba, T., Watanabe, N., Kubo, T., Nanao, H., Minami, I. and Mori, S., "Effects of Carboxylic Acids on Friction and Wear Reducing Properties for Alkylmethylimidazolium Derived Ionic liquids," Tribology Online, 1, 2, 2006, 40-43.

[18] Okubo, H., Watanabe, S., Tadokoro, C. and Sasaki, S., "Effect of Concentration of Zinc Dialkyldithiophosphate on the Tribological Properties of Tetrahedral Amorphous Carbon Films in Presence of Organic Friction Modifiers," Tribology International, 94, 2016, 446457. 
[19] Okubo, H., Watanabe, S., Tadokoro, C. and Sasaki, S., "Effects of Structure of Zinc Dialkyldithiophosphates on Tribological Properties of Tetrahedral Amorphous Carbon Film under Boundary Lubrication," Tribology International, 98, 2016, 26-40.

[20] Okubo, H., Tadokoro, C. and Sasaki, S., "Tribological Properties of a Tetrahedral Amorphous Carbon (ta-C) Film under Boundary Lubrication in the Presence of Organic Friction Modifiers and Zinc Dialkyldithiophosphate (ZDDP)," Wear, 332-333, 2015, 1293-1302.

[21] Spikes, H., "The History and Mechanisms of ZDDP," Tribology Letters, 17, 2004, 469-489.

[22] Okubo, H., Watanabe, S., Tadokoro, C., Hirata, Y. and Sasaki, S., "Effects of Molecular Structure of Zinc Dialkyldithiophosphates on Tribological Properties of a Hydrogenated Amorphous Carbon Film under Boundary Lubrication," Tribology Online, 12, 5, 2017, 221-228.

[23] Qu, J., Luo, H., Chi, M., Ma, C., Blau, P. J., Dai, S. and Viola, M. B., "Comparison of an Oil-Miscible Ionic Liquid and ZDDP as a Lubricant Anti-Wear Additive," Tribology International, 71, 2014, 88-97.

[24] Watanabe, S., Nakano, M., Miyake, K., Tadokoro, C. and Sasaki, S., "Vibrational Spectroscopic Study on Lubrication and Corrosive Wear Mechanisms of Imidazolium Based Ionic Liquids," Ionic Liquids - Current State of the Art, InTech, Rijeka, 2015.

[25] Swatloski, R. P., Holbrey, J. D. and Rogers, R. D., “Ionic Liquids are not Always Green: Hydrolysis of 1-Butyl-3-methylimidazolium Hexafluorophosphates," Green Chemistry, 5, 2003, 361-363.

[26] Wamser, C. A., "Hydrolysis of Fluoboric Acid in Aqueous Solution," Journal of the American Chemical Society, 70, 3, 1948, 1209-1215.

[27] Arias-Pardilla, J., Espinosa, T. and Bermúdez, M. D., “Ionic Liquids in Surface Protection," Electrochemical Ionic Liquids, 2, 2015, 533-561.

[28] Kawada, S., Watanabe, S., Kondo, Y., Tsuboi, R. and Sasaki, S., "Tribochemical Reactions of Ionic Liquids under Vacuum Conditions,"
Tribology Letters, 54, 2014, 309-315.

[29] Totolin, V., Minami, I., Gabler, C., Vrenner, J. and Dörr, N., "Lubrication Mechanism of Phosphonium Phosphate Ionic Liquid Additive in Alkylborane-Imidazole Complexes," Tribology Letters, 53, 2014, 421-432.

[30] Kondo, Y., Koyama, T., Tsuboi, R., Nakano, M., Miyake, K. and Sasaki, S., "Tribological Performance of Halogen-Free Ionic Liquids as Lubricants of Hard Coatings and Ceramics," Tribology Letters, 51, 2013, 243-249.

[31] Shah, F. U., Glavatskih, S. and Oleg, N. A., "Boron in Tribology: From Borates to Ionic Liquids," Tribology Letters, 51, 2013, 281-301.

[32] Kawada, S., Watanabe, S., Tsuboi, R., Sasaki, S. and Prakash, B., "Lubrication Mechanism of Halogen-Free Ionic Liquids," Tribology Online, 12, 4, 2017, 155-161.

[33] Kawada, S., Watanabe, S., Tadokoro, C. and Sasaki, S., "Effects of Alkyl Chain Length of Sulfate and Phosphate Anion-Based Ionic Liquids on Tribochemical Reactions," Tribology Letters, 66, 8, 2018.

[34] Minami, I., Inada, T. and Okada, Y., "Tribological Properties of Halogen-Free Ionic Liquids," Proceedings of the Institution of Mechanical Engineers, Part J: Journal of Engineering Tribology, 226, 11, 2012, 891-902.

[35] Kawada, S., Watanabe, S., Tadokoro, C., Tsuboi, R. and Sasaki, S., "Lubricationg Mechanism of Cyano-Based Ionic Liquids on Nascent Steel Surface," Tribology International, 119, 2018, 474-480.

[36] Lu, R., Mori, S., Kobayashi, K. and Nanao, H., "Study of Tribochemical Decomposition of Ionic Liquids on a Nascent Steel Surface," Applied Surface Science, 255, 2009, 8965-8971.

[37] Liu, X. Q., Zhou, F., Liang, Y. M. and Liu, W., “Tribological Performance of Phosphonium Based Ionic Liquids for an Aluminum-on-Steel System and Opinions on Lubrication Mechanism," Wear, 261, 2006, 1174-1179. 